\title{
The Effect on Post-Operative Intraocular Lens Centration by Manual Intraoperative Centration versus Auto-Centration
}

This article was published in the following Dove Press journal: Clinical Ophthalmology

\author{
Ehud I Assia ${ }^{1,2}$ \\ John XH Wong $\mathbb{D}^{2,3}$ \\ Yoram Shochot ${ }^{3}$ \\ 'Ein-Tal Eye Center, Tel Aviv, Israel; \\ ${ }^{2}$ Center for Applied Eye Research, \\ Department of Ophthalmology, Meir \\ Medical Center, Affiliated with the \\ Sackler School of Medicine, Tel Aviv \\ University, Kfar Saba, Israel; ${ }^{3}$ National \\ Healthcare Group Eye Institute, Tan Tock \\ Seng Hospital, Singapore
}

Introduction: To determine if intraoperative manual centration of the intraocular lens (IOL) during cataract surgery results in better early post-operative centration. It is common practice for cataract surgeons to align intraocular lens centration to the visual axis by manual intraoperative manipulation of the intraocular lens. We aim to compare post-operative intraocular lens centration between intraocular lenses that were allowed spontaneous positioning in the capsular bag and IOLs that were manually centred during implantation.

Materials and Methods: One hundred and twenty-five consecutive eyes that underwent either femtosecond laser-assisted cataract surgery (FLACS) or phacoemulsification and IOL (monofocal/toric/multifocal) implantation by a single surgeon were included. Post-operative IOL centration at 4 weeks was assessed and measured on a slit-lamp by a masked observer. Results: A total of 17 (13.6\%) IOLs were off-centered to some extent at 4 weeks postoperatively. All the decentered IOLs were graded as minimal or mild $(<0.5 \mathrm{~mm})$ decentration. There was no statistically significant difference in the proportion of decentered IOLs between the manual centration group and non-centration group $(\mathrm{p}=0.59)$.

Conclusion: The final position of the IOL is not dependent on manual centration but rather on the design and symmetry of the IOL, as well as the integrity of the capsular bag.

Keywords: intraocular lens, centration, phacoemulsification, femtosecond

\section{Introduction}

Proper intraocular lens (IOL) placement and centration affects the visual outcomes of patients undergoing cataract surgery, and is crucial in aspheric, ${ }^{1-3}$ toric and multifocal $\mathrm{IOL}^{4}$ implantation. IOL decentration can lead to patient dissatisfaction resulting from refractive errors and higher-order aberrations with consequent decrease in the quality of vision. ${ }^{1-3}$ In cases when the centre of the pupil is not aligned with the cornea vertex, some surgeons advocated manual positioning of the implanted lens relative to the pupillary aperture. Apart from centering the IOL on the visual axis by lining up the purkinje images, ${ }^{6-8}$ some surgeon push the IOL optic down against the posterior capsule $e^{9,10}$ as a final step in IOL implantation believing that this manoeuvre will keep the IOL in the desired position due to the sticky nature of the hydrophobic material and adherence of the IOL to the posterior capsule.

This paper compares the early post-operative IOL centration between IOLs that were allowed spontaneous positioning in the capsular bag and IOLs that were carefully centred and pushed posteriorly against the posterior capsule during implantation.
Correspondence: Ehud I Assia

Director, Center for Applied Eye

Research, Department of Ophthalmology,

Meir Medical Center, 59 Tshernichovsky,

Tel +972-9-747I 527

Fax +972-9-7472427

Email ehud.assia@clalit.org.il 


\section{Materials and Methods}

This study comprised of 125 consecutive eyes that underwent either femtosecond laser-assisted cataract surgery (FLACS) or phacoemulsification and intraocular lens implantation by a single surgeon at the Ein-Tal Eye Centre, Tel Aviv, Israel. To reflect clinical practice, all types of intraocular lenses were included, and no cases was excluded because of IOL material, design or configuration. Formal approval from the local Institutional Review Board, in accordance with the Declaration of Helsinki, was obtained for the study. Informed consent was obtained by all patients included in the study.

\section{Surgical Technique}

All surgeries were performed using the same technique and the same femtosecond-laser platform/phacoemulsification machine. In eyes that underwent FLACS, a $5.0 \mathrm{~mm}$ capsulotomy was created, while a continuous curvilinear capsulorhexis (CCC) as close to $5.0 \mathrm{~mm}$ as possible was performed in non-FLACS case. All patients were operated by superior approach and had the main corneal incision of $2.2 \mathrm{~mm}$ sited at the supero-temporal (right eyes) or supero-nasal cornea (left eyes). This was followed by phacoemulsification and IOL implantation. In the manual centration group, the IOL was manually centred and then gentle pressure was applied on the optic of the IOL to press it posteriorly against the posterior capsule. In the non-centration group, no manipulation of the IOL was performed after observing that the haptics had unfolded beyond the anterior capsular rim. For eyes with toric IOLs in the non-centration group, the IOLs were rotated to the proper axis but no attempts were made to keep the optic centred.

\section{Patient Evaluation}

All patients were examined at 1 day, 1 week and 4 weeks post-operatively. Slit-lamp examination was performed by a single ophthalmologist who was blinded to the intraoperative centration procedure performed. IOL centration was recorded on slit-lamp examination at 4 weeks postoperatively by assessing the distance between the edges of the IOL optic to the edges of the dilated pupil after maximum dilation. Decentration was graded as follows: No decentration (Central), minimal $(<0.25 \mathrm{~mm})$, mild $(0.25 \mathrm{~mm}-<0.5 \mathrm{~mm})$, moderate $(0.5 \mathrm{~mm}-1.0 \mathrm{~mm})$, severe $(>1.0 \mathrm{~mm})$.

\section{Statistical Analysis}

Data analyses were performed with IBM SPSS Statistics (Version 19, IBM Corp, New York, USA). Comparison of proportions between the manual centration/non-centration groups and FLACS/manual CCC groups were performed using Chi-square test.

\section{Results}

The study included 125 eyes (66 right and 59 left) of 125 consecutive patients. FLACS was performed on 76 eyes and routine phacoemulsification in 49 eyes. There were 66 eyes in the manual centration group and 59 eyes in the noncentration group. IOLs from 4 manufacturers were used in these patients which comprised of hydrophobic and hydrophilic IOLs. These IOLs were SA60AT, SN60WF, MA60MA, SN6AT, TFNT (Alcon Laboratories, Inc., Fort Worth, Texas, USA), AAB00, ZCB00, ZCT, ZXR00, ZXT (Abbott Medical Optics, Inc., Santa Ana, California, USA), Micro F, Pod FT (PhysIOL, Liège, Belgium), SeeLens AF, BunnyLens AF, VisTor (Hanita, Israel). Table 1 shows the surgical characteristics of the patients.

A total of 17 (13.6\%) IOLs were decentered to some extent at 4 weeks post-operatively. All the decentered IOLs were graded as barely noticeable (minimal) or mild $(<0.5 \mathrm{~mm})$ decentration. None of the decentered IOLs had any clinical significance and the optic filled the entire optical axis (central $5 \mathrm{~mm}$ ). There was no statistically significant difference in the proportion of decentered IOLs between the manual centration group and noncentration group. Further subgroup analysis between FLACS/non-FLACS eyes similarly did not reveal any significant difference in decentration of IOLs. Subgroup analysis of eyes that were implanted with SA60AT ( $p=$ $0.20)$ and $\mathrm{AAB} 00(\mathrm{p}=0.75)$, did not show a statistically significant difference in proportion of decentration. Another subgroup analysis excluding toric IOLs also did not yield any significant difference. These results are summarized in Table 2.

\section{Discussion}

Centration of PC-IOLs located within the capsular bag may affect optical results, especially multifocal IOLs and more specifically refractive lenses. ${ }^{4}$ In eyes with offcentered pupil or a large angle kappa, the optical center of the IOL may not be aligned with the optical axis of the eye. Some surgeons recommend to deviate the position of the IOL optic during surgery so that it may better fit to the 
Table I Surgical Characteristics

\begin{tabular}{|l|l|}
\hline Laterality, $\mathbf{n}$ (\%) & \\
\hline Right & $66(52.8)$ \\
Left & $59(47.2)$ \\
\hline Capsulotomy technique, $\mathbf{n}(\%)$ & \\
Femtosecond-laser capsulotomy & $76(60.8)$ \\
Manual CCC & $49(39.2)$ \\
\hline IOL centration technique, $\mathbf{n}$ (\%) & \\
Manual & $66(52.8)$ \\
None & $59(47.2)$ \\
\hline IOL type/model, $\mathbf{n}$ (\%) & \\
Monofocal & \\
SA60AT & $43(34.4)$ \\
SN60WF & $5(4.0)$ \\
MA60MA & $2(1.6)$ \\
AAB00 & $30(24.0)$ \\
ZCB00 & $5(4.0)$ \\
SeeLens AF & $5(4.0)$ \\
BunnyLens AF & 108.0 \\
\hline Monofocal toric & $2(1.6)$ \\
SN6AT & \\
ZCT & $6(4.8)$ \\
VisTor & $1(0.8)$ \\
\hline Trifocal & $3(2.4)$ \\
Micro F & \\
TFNT & $5(4.8)$ \\
\hline Trifocal Toric & \\
Pod FT & \\
\hline EDoF & \\
EDoF00 toric & \\
\hline
\end{tabular}

Abbreviations: CCC, continuous curvilinear capsulorhexis; EDoF, extended depth of focus.

center of the constricted pupil. Pressing the optic against the posterior capsule, especially lenses made of "sticky" hydrophobic acrylic material, may provide better longterm position of the optical center of the IOL relative to the pupil. Others debate this concept and believe that IOL final position in primarily affected by the physical properties of the lens material and its design and configuration. We did not find any previous study to support any of the two approaches.

The centration of an IOL within the capsular bag is influenced by the interaction between the IOL and the capsular bag. IOL factors include the optic and haptic material, ${ }^{11}$ the overall IOL length in relation to the capsular bag diameter, and the inherent ability of the haptics to withstand compressive forces of a contracting capsular bag. ${ }^{12}$ Capsular bag factors include CCC centration, size and integrity. ${ }^{13}$ The biocompatibility of an IOL is dependent on its material. Post-operative changes to the capsular bag such as anterior capsular contraction and posterior capsular opacification vary depending on the IOL material. ${ }^{14,15}$ Capsular bag contraction exerts a force on the IOL and may lead to decentration and tilt. ${ }^{16}$ Oner et al reported better early and late post-operative IOL centration in eyes with complete CCCs compared to CCCs with radial tears. ${ }^{13}$ In a study comparing IOL centration after manual versus femtosecond capsulotomy, Nagy et al demonstrated correlation between decentration and axial length in the manual CCC group but not in the femtosecond capsulotomy group. Improved centration in the femtosecond capsulotomy group was attributed to the predictable size and shape of the capsulotomy, which resulted in complete overlap of the capsulotomy edge with the anterior edge of the optic. ${ }^{17}$ Our study did not reveal a statistically significant difference in the proportion of eyes that had IOL decentration between eyes that had femtosecond capsulotomy and manual CCC. The overall rate of any degree of decentration was low (13.6\%) amongst our study group, with no IOL measured to have more than $0.5 \mathrm{~mm}$ of decentration. Decentration of less than $0.25 \mathrm{~mm}$ is barely noticeable and IOL position would typically be described by most clinicians as "central". Decentration of $0.25-0.50 \mathrm{~mm}$ is noticeable in a slitlamp examination but is clinically insignificant and the lens optic edges are outside of the pupillary margin even when the pupil is naturally dilated in a dim light.

In order to reduce higher order aberrations (HOA), excellent centration of aspheric IOLs is required. ${ }^{5}$ Holladay et al reported the critical amount of decentration for an aspheric IOL as approximately $0.4 \mathrm{~mm}$, beyond which it would lose its optical advantage over a spherical IOL. ${ }^{18}$ Decentration of multifocal IOLs has been shown to decrease visual acuity. ${ }^{4}$ Despite most modern IOLs being designed to self-centre within the capsular bag, ${ }^{19}$ an IOL may not centre well due to an asymmetrically shaped or too large or small capsular bag relative to the IOL. ${ }^{10}$ The results from our study suggest that the final position of the IOL is not dependent on manual centration but rather on the design and symmetry of the IOL, as well as the integrity of the capsular bag.

The present study was designed as a pilot observation of non-selected IOLs and surgical techniques to 
Table 2 Comparing Proportion of IOL Decentration Between Manual Centration and Non-Centration Groups with Subset Analysis Between FLACS and Non-FLACs Eyes (Chi-Square Test)

\begin{tabular}{|c|c|c|c|c|}
\hline All IOLs (Including Torics) & & & & \\
\hline $\begin{array}{l}\text { Manual Centration Group, } \\
\text { n (\%) }\end{array}$ & $\begin{array}{l}\text { Non-Centration Group, } \\
\text { n (\%) }\end{array}$ & & & p-value \\
\hline $66(52.8)$ & $59(47.2)$ & & & \\
\hline $\begin{array}{l}\text { Total centered, } n(\%) \\
56(84.8)\end{array}$ & $\begin{array}{l}\text { Total centered, } n(\%) \\
52(88.1)\end{array}$ & & & 0.59 \\
\hline $\begin{array}{l}\text { Minimal decentered, } n(\%) \\
6(9.1)\end{array}$ & $\begin{array}{l}\text { Minimal decentered, } n(\%) \\
5(8.5)\end{array}$ & & & 0.91 \\
\hline $\begin{array}{l}\text { Mild decentered, } \mathrm{n}(\%) \\
4(6.1)\end{array}$ & $\begin{array}{l}\text { Mild decentered, n (\%) } \\
2(3.4)\end{array}$ & & & 0.48 \\
\hline $\begin{array}{l}\text { FLACS manual centration } \\
\text { group, } \mathbf{n}(\%)\end{array}$ & $\begin{array}{l}\text { FLACS non-centration } \\
\text { group, } \mathrm{n}(\%)\end{array}$ & $\begin{array}{l}\text { Phaco manual centration } \\
\text { group, } \mathbf{n}(\%)\end{array}$ & $\begin{array}{l}\text { Phaco non-centration } \\
\text { group, } \mathbf{n}(\%)\end{array}$ & p-value \\
\hline $43(34.4)$ & $33(26.4)$ & $23(18.4)$ & $26(20.8)$ & \\
\hline \multirow[t]{2}{*}{$\begin{array}{l}\text { Total centered, } \mathrm{n}(\%) \\
37(86.0)\end{array}$} & $\begin{array}{l}\text { Total centered, } n(\%) \\
27(81.8)\end{array}$ & & & 0.62 \\
\hline & & $\begin{array}{l}\text { Total centered, } \mathrm{n}(\%) \\
19(82.6)\end{array}$ & $\begin{array}{l}\text { Total centered, } \mathrm{n}(\%) \\
25(96.2)\end{array}$ & 0.12 \\
\hline \multirow[t]{2}{*}{$\begin{array}{l}\text { Total centered, } n(\%) \\
37(86.0)\end{array}$} & & $\begin{array}{l}\text { Total centered, } \mathrm{n}(\%) \\
19(82.6)\end{array}$ & & 0.72 \\
\hline & $\begin{array}{l}\text { Total centered, } n(\%) \\
27(81.8)\end{array}$ & & $\begin{array}{l}\text { Total centered, } n(\%) \\
25(96.2)\end{array}$ & 0.09 \\
\hline $\begin{array}{l}\text { Non-toric IOLs } \\
\text { Manual centration group, } \\
\text { n (\%) }\end{array}$ & $\begin{array}{l}\text { Non-centration group, } \\
\text { n (\%) }\end{array}$ & & & p-value \\
\hline $51(47.2)$ & $57(58.2)$ & & & \\
\hline $\begin{array}{l}\text { Total centered, } n(\%) \\
4 \mathrm{I}(80.4)\end{array}$ & $\begin{array}{l}\text { Total centered, n (\%) } \\
51(89.5)\end{array}$ & & & 0.18 \\
\hline $\begin{array}{l}\text { Minimal decentered, } \mathrm{n}(\%) \\
6 \text { (II.8) }\end{array}$ & $\begin{array}{l}\text { Minimal decentered, } \mathrm{n}(\%) \\
5(8.8)\end{array}$ & & & 0.44 \\
\hline $\begin{array}{l}\text { Mild decentered, n (\%) } \\
0(0.0)\end{array}$ & $\begin{array}{l}\text { Mild decentered, n (\%) } \\
\text { I (2.0) }\end{array}$ & & & - \\
\hline
\end{tabular}

Abbreviation: FLACS, femtosecond laser-assisted cataract surgery.

determine whether there is a need for a larger-scale investigation of specific lenses using accurate measuring techniques. We emphasized that our methodology was chosen deliberately to apply the results to practical clinical practice, where multiple types of IOL are used in a practice. Had we chosen a single lens design, a single optic material or a single surgical technique, it could have been debated that the principle of auto-centration is limited to specific lenses or technique. Although this is a significant limitation, we believe this reflects the reallife practice as most surgeons use multiple types of IOLs. Our results suggest that auto-centration is achieved by all IOLs provided the lens design is symmetrical and proportional. Moreover, subgroup analysis of eyes that were implanted with SA60AT $(p=0.20)$ and AAB00 ( $\mathrm{p}=0.75)$, which constitute $58.8 \%$ (58 eyes), did not show a statistically significant difference in proportion of decentration. Also, analysing only eyes with 
non-toric implanted did not affect final results. We assessed IOL decentration during slit-lamp examination of the patient by measuring 2 distances between IOL optic edges to the pupil edges 180 degrees apart on the axis that show the greatest difference in values. The difference between these 2 values represent the amount of decentration. This method may be limited by asymmetric pupillary dilatation. More sophisticated methods of measuring IOL decentration using Scheimpflug imaging, anterior segment ocular coherence tomography (OCT) and photographic analysis have been described. $^{20}$ These methods have their own limitations. Measurements from Scheimpflug imaging can be inaccurate because of alignment issues from 1 visit to another or because of magnification and distortion effects from the Scheimpflug camera. ${ }^{21-23}$ Here again, practical measurements representing the routine eye examination postoperatively was chosen to apply the clinical results to common practice.

In conclusion, our data suggests that final IOL centration within the capsular bag in the early post-operative period is not affected by manual positioning during implantation. In spite of our results, we do not recommend that surgeons ignore the importance of careful IOL placement within the capsular bag during surgery. On the contrary, central position of the IOL and pushing the optic backward to deepen the anterior chamber are the proper routine of the quality surgery. Nevertheless, we believe that a proper sized IOL of at least $12 \mathrm{~mm}$ overall length, will auto-centre provided that there is no damage to the optic or haptic during its implantation, and that the IOL is implanted into an intact capsular bag with central anterior capsulotomy and intact zonules. Moreover, positioning the IOL in a non-centred location, to fit an off-centred pupil, will most probably result in auto-centration of the IOL in spite of the surgeon's attempt to de-centre the IOL. More studies with more sophisticated measurements of specific IOLs are required to demonstrate the principle of autocentration.

\section{Compliance with Ethical Standards}

Appropriate ethical approval was obtained from the IRB Helsinki Committee of Meir Medical Center, Kfar Saba, Israel. All procedures performed in the study were in accordance with the ethical standards of the institutional and/or national research committee and with the 1964 Helsinki declaration and its later amendments or comparable ethical standards.

\section{Funding}

This study is not funded by any grant.

\section{Disclosure}

Ehud Assia MD reports financial and proprietary interests for Hanita Lenses, Biotechnology General, Vision Care Technologies, APX Ophthalmology, IOPtima, VisiDome, CorNeat; and personal fees from Hanita Lenses, outside the submitted work. The authors report no other potential conflicts of interest for this work.

\section{References}

1. Altmann GE, Nichamin LD, Lane SS, Pepose JS. Optical performance of 3 intraocular lens designs in the presence of decentration. $J$ Cataract Refract Surg. 2005;31:574-585.

2. Akkin C, Ozler SA, Mentes J. Tilt and decentration of bag-fixated intraocular lenses: a comparative study between capsulorhexis and envelope techniques. Doc Ophthalmol. 1994;87(3):199-209. doi:10.1007/ BF01203850

3. Eppig T, Scholz K, Loffler A, Meßner A, Langenbucher A. Effect of decentration and tilt on the image quality of aspheric intraocular lens designs in a model eye. $J$ Cataract Refract Surg. 2009;35 (6):1091-1100. doi:10.1016/j.jcrs.2009.01.034

4. Hayashi K, Hayashi H, Nakao F, Hayashi F. Correlation between pupillary size and intraocular lens decentration and visual acuity of a zonal progressive multifocal lens and a monofocal lens. Ophthalmology. 2001;108(11):2011-2017. doi:10.1016/S01616420(01)00756-4

5. Wang L, Koch DD. Effect of decentration of wavefront-corrected intraocular lenses on the higher-order aberrations of the eye. Arch Ophthalmol. 2005;123(9):1226-1230. doi:10.1001/archopht.123.9.1226

6. Chang DH, Waring GO. The subject-fixated coaxially sighted corneal light reflex: a clinical marker for centration of refractive treatments and devices. Am J Ophthalmol. 2014;158(5):863-874. doi:10.1016/j. ajo.2014.06.028

7. Thompson V. Streamlined method for anchoring cataract surgery and intraocular lens centration on the patient's visual axis. $J$ Cataract Refract Surg. 2018;44(5):528-533. doi:10.1016/j. jcrs.2018.02.013

8. Melki SA, Harissi-Dagher M. Coaxially sighted intraocular lens light reflex for centration of the multifocal single piece intraocular lens. Can J Ophthalmol. 2011;46(4):319-321. doi:10.1016/j.jcjo.2011.06.007.

9. Devgan U Improving phacoemulsification: positioning Toric IOLs. Cataract \& refractive surgery today.2010. https://crstoday.com/arti cles/2010-jan/focus-on-phacoemulsification-improvingphacoemulsification/. Accessed 6 October 2019.

10. Baldassare R. Nine Pearls for Centering the Tecnis Symfony IOL. CRSTEurope 2016. https://crstodayeurope.com/articles/2016-sep/ninepearls-for-centering-the-tecnis-symfony-iol/. Accessed 6 October 2019

11. Hayashi K, Hayashi H, Nakao F, Hayashi F. Anterior capsule contraction and intraocular lens decentration and tilt after hydrogel lens implantation. Br J Ophthalmol. 2001;85(11):1294-1297. doi:10.11 36/bjo.85.11.1294

12. O'Donnell FE, Santos BA. In vitro, adhesive fixation of a posterior chamber lens optic: implications for lens centration and posterior capsule opacification. J Cataract Refract Surg. 1991;17(3):384-385. doi:10.1016/S0886-3350(13)80841-3

13. Oner FH, Durak I, Soylev M, Ergin M. Long-term results of various anterior capsulotomies and radial tears on intraocular lens centration. Ophthalmic Surg Lasers. 2001;32(2):118-123. 
14. Hayashi K, Hayashi H, Nakao F, Hayashi F. Reduction in the area of the anterior capsule opening after polymethylmethacrylate, silicone, and soft acrylic intraocular lens implantation. Am J Ophthalmol. 1997;123(4):441-447. doi:10.1016/S0002-9394(14)70169-2

15. Hollick EJ, Spalton DJ, Ursell PG, et al. The effect of polymethylmethacrylate, silicone, and polyacrylic intraocular lenses on posterior capsular opacification 3 years after cataract surgery. Ophthalmology. 1999;106(1):49-55. doi:10.1016/S0161-6420(99) 90047-7

16. Roshdy MM, Riad RF, Morkos FF, Hassouna AK, Wahba SS. Effect of a single-piece aspheric hydrophobic acrylic intraocular lens design on centration and rotation. J Cataract Refract Surg. 2013;39 (3):408-413. doi:10.1016/j.jcrs.2012.09.020

17. Nagy ZZ, Kránitz K, Takacs AI, Miháltz K, Kovács I, Knorz MC. Comparison of intraocular lens decentration parameters after femtosecond and manual capsulotomies. J Refract Surg. 2011;27 (8):564-569. doi:10.3928/1081597X-20110607-01.

18. Holladay JT, Piers PA, Koranyi G, van der Mooren M, Norrby NES. A new intraocular lens design to reduce spherical aberration of pseudophakic eyes. $J$ Refract Surg. 2002;18:683-691.
19. Roach L. Centration of IOLs: challenges, Variables, and Advice for Optimal Outcomes. EyeNet Magazine. 2013. https://www.aao.org/ eyenet/article/centration-of-iols-challenges-variables-advice-opt? april-2013. Accessed 6 October 2019.

20. Monte's-Mico R, Cervino A, Ferrer-Blasco T. Intraocular lens centration and stability: efficacy of current technique and technology. Curr Opin Ophthalmol. 2009;20(1):33-36. doi:10.1097/ ICU.0b013e328318591c

21. de Castro A, Rosales P, Marcos S. Tilt and decentration of intraocular lenses in vivo from Purkinje and Scheimpflug imaging: validation study. J Cataract Refract Surg. 2007;33(3):418-429. doi:10.1016/j. jcrs.2006.10.054

22. Huebscher H, Fink W, Steinbruck D, Seiler T. Scheimpflug records without distortion - a mythos? Ophthalmic Res. 1999;31(2):134-139. doi:10.1159/000055525

23. Koretz JF, Strenk SA, Strenk LM, Semmlow JL. Scheimpflug and high-resolution magnetic resonance imaging of the anterior segment: a comparative study. J Opt Soc Am a Opt Image Sci Vis. 2004;21 (3):346-354. doi:10.1364/JOSAA.21.000346
Clinical Ophthalmology

\section{Publish your work in this journal}

Clinical Ophthalmology is an international, peer-reviewed journal covering all subspecialties within ophthalmology. Key topics include: Optometry; Visual science; Pharmacology and drug therapy in eye diseases; Basic Sciences; Primary and Secondary eye care; Patient Safety and Quality of Care Improvements. This journal is indexed on PubMed

\section{Dovepress}

Central and CAS, and is the official journal of The Society of Clinical Ophthalmology (SCO). The manuscript management system is completely online and includes a very quick and fair peer-review system, which is all easy to use. Visit http://www.dovepress.com/ testimonials.php to read real quotes from published authors. 